\title{
Surgical management of pulmonary hydatid cysts in children
}

\author{
Mustafa Elburio, Eid Abdul Gani
}

\begin{abstract}
Background - Hydatid disease is common in Libya with a prevalence of $2 \%$. Surgery of pulmonary hydatid disease remains the best treatment and aims to remove the cyst or its remnants and obliterate the residual cavity.

Methods - Forty three consecutive patients under 15 years of age were investigated by plain chest radiography, ultrasonography of the abdomen, and indirect haemagglutination tests. At thoracotomy the parasite or its remnants were removed and the bronchial fistula sutured.

Results - All but four of the patients were discharged within 12 days. These four had had their large cavities obliterated by purse string sutures and developed air fluid levels with cavity reformation at the cyst site. They were treated conservatively by physiotherapy and antibiotics and remained in hospital for 2-3 weeks. There was only one recurrence after three years of follow up.

Conclusions - Pulmonary hydatid cysts in children can be treated successfully by evacuation and obliteration. The methods described can also be applied to adults. (Thorax 1995;50:396-398)
\end{abstract}

Keywords: hydatid disease, children, thoracic surgery.

Hydatid disease is common in Libya with a prevalence of $2 \%$. Pulmonary involvement is second in frequency after the liver. ${ }^{12}$ The effectiveness of drug treatment is still a subject for debate. Mebendazole and albendazole are used mainly for hydatid disease of the liver and have limitations. ${ }^{34}$ Although drug treatment may succeed in sterilising cysts, surgery is often required whether or not drugs are used. The optimal surgical technique remains uncertain. We present the results of surgical treatment of pulmonary hydatid disease by enucleation of the intact cysts or removal of the remnants of the ruptured ones and obliteration of the residual cavities without resection.

Thoracic Surgery, Faculty of Medicine, Al-Arab Medical University, Benghazi, Libya

M Elburio

E A Gani

Reprint requests to: Dr M Elburjo, Post Box 7888, Benghazi, Libya.

Received 9 August 1993 Returned to authors 12 November 1993 Revised version received 31 May 1994 Accepted for publication 25 October 1994

\author{
Methods \\ Between January 1985 and December 199143 \\ children under the age of 15 years were treated \\ surgically at the Al-Jala Hospital, Benghazi, \\ Libya. All were investigated by chest radio- \\ graphy, ultasonography of the abdomen, and \\ indirect haemagglutination tests.
}

OPERATIVE PROCEDURE

A standard thoracotomy incision was made on the affected side and pleural adhesions were released. Hypertonic saline packs $(20 \%)$ were placed around the affected lung to avoid con- $\vec{\circ}$ tamination of the pleural cavity if a cyst ruptured. The most glistening part of the "pericyst layer" over the cyst was gently incised. The incision was widened and the lung inflated further to help deliver the cyst. If the cyst ruptured, suction was used and the cyst irrigated with hypertonic saline. Where a cyst $\mathscr{}$ had already ruptured the pericyst was opened 은 and the parasitic remnants removed. Whether the cyst was intact or not, the cystobronchial openings were closed with non-absorbable $2 / 0$ silk sutures. Small pericyst cavities were closed with silk purse string sutures starting from the bottom. In large cavities this method of suturing was difficult because the sutures tore through the lung tissue. Additionally, we found that it could lead to distortion of the residual lobe or lung. We therefore began to use interrupted sutures in the long axis of the cavity in rows from the bottom upwards (fig 1, table 1). These sutures were easy to insert, did not cut through the tissue, and did not cause distortion. This method was also better for multiple cysts.

Bilateral disease needed two thoracotomies performed on separate occasions four weeks apart. Ampicillin $50 \mathrm{mg} / \mathrm{kg}$ six hourly and gentamicin $2.5 \mathrm{mg} / \mathrm{kg}$ daily were started one day before surgery and continued for a further six days thereafter. Postoperatively two intercostal drainage tubes with underwater seals were used, one at the apex and the other at the lung base. These remained in situ for 2-8 days.

\section{Results}

Forty three patients ( 25 boys) under the age of 15 years were studied. The youngest was three. Almost all were symptomatic with cough being the commonest symptom (table 2 ). The ? most helpful diagnostic tool was a plain chest 0 radiograph for both intact and ruptured cysts (table 3, figs 2-4). Radiographic examination showed 49 cysts in the 43 patients, 32 of which were on the right (19 in the lower lobe, seven in the middle lobe, and six in the upper lobe). On the left the 17 cysts were distributed 11 to the lower lobe and six to the upper. There were bilateral cysts in four patients. In five cases ultrasonographic examination of the abdomen showed liver involvement. A positive indirect haemagglutination test was present in 18 of 28 patients.

Following surgery there were no deaths and no major complications. The follow up period

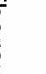

.



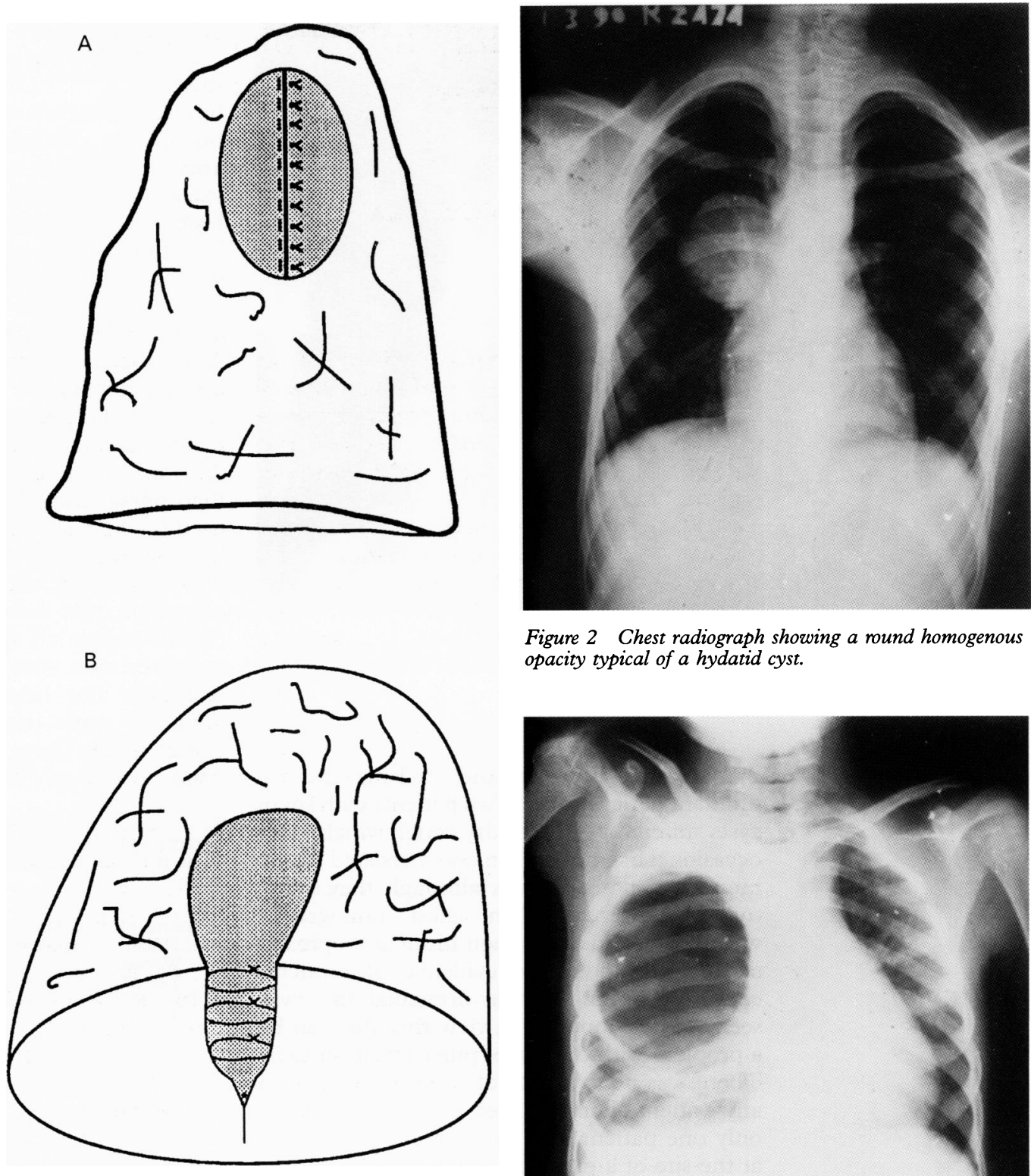

Figure 1 The long axis method. (A) Hydatid cavity seen from above with interrupted sutures at its base. (B) Cornal section of a cavity after applying the interrupted sutures.

Table 1 Surgical procedures

\begin{tabular}{lll}
\hline & Small cavities & Large cavities \\
\hline Long axis & - & 9 \\
Purse string & 25 & $7^{*}$ \\
Left open & 2 & - \\
\hline
\end{tabular}

* Four patients developed air fluid level within seven days of the operation.

\section{Table 2 Occurrence of symptoms}

\begin{tabular}{ll}
\hline Symptoms & No. of patients \\
\hline Cough (alone) & 14 \\
Cough + fever & 16 \\
Haemoptysis & 9 \\
Pain & 2 \\
Asymptomatic incidental findings & 2 \\
Total & 43 \\
\hline
\end{tabular}

ranged from six months to three years. The nine patients who had their cavities obliterated by the longitudinal method did not develop any complications. Thirty two patients had their cavities obliterated by the purse string
Figure 2 Chest radiograph showing a round homogenous opacity typical of a hydatid cyst.

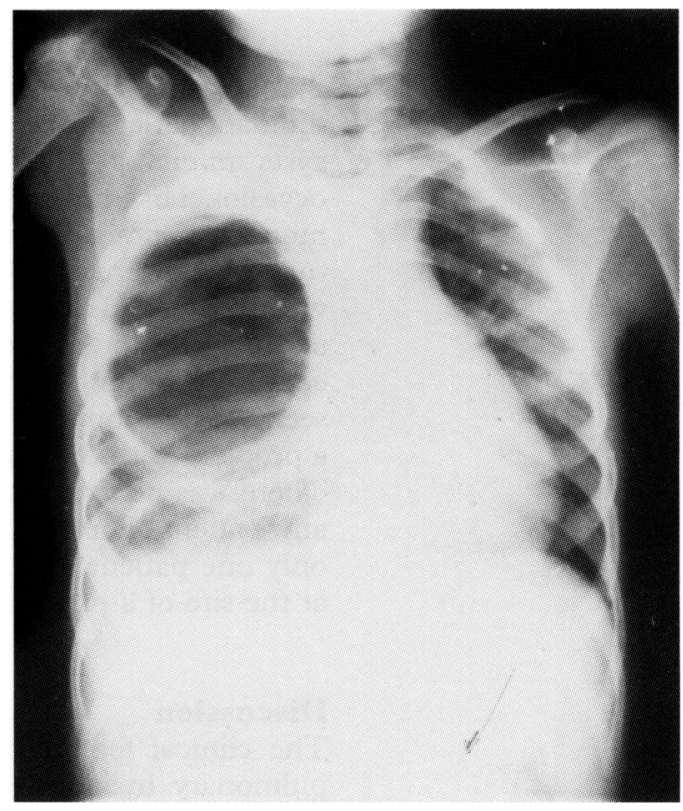

Figure 3 Chest radiograph showing a large hydatid cavity in the right lung.

Table 3 Radiological findings

\begin{tabular}{lc}
\hline Findings & No. of patients \\
\hline Round opacity & 28 \\
Cavity (no fluid) & 4 \\
Hydropneumothorax & 5 \\
Cavity with fluid (air fluid level) & 6 \\
Total & 43 \\
\hline
\end{tabular}

method and seven of them had large cavities. An air fluid level appeared at the site of the cyst in four of these seven patients. These collections were probably due to the sutures cutting through the lung tissue while the external suture remained. They were treated conservatively with antibiotics and physiotherapy, and all recovered fully but remained in hospital 2-3 weeks longer than the other patients. In two other patients the cavities were small and superficial. These were left open after closing 


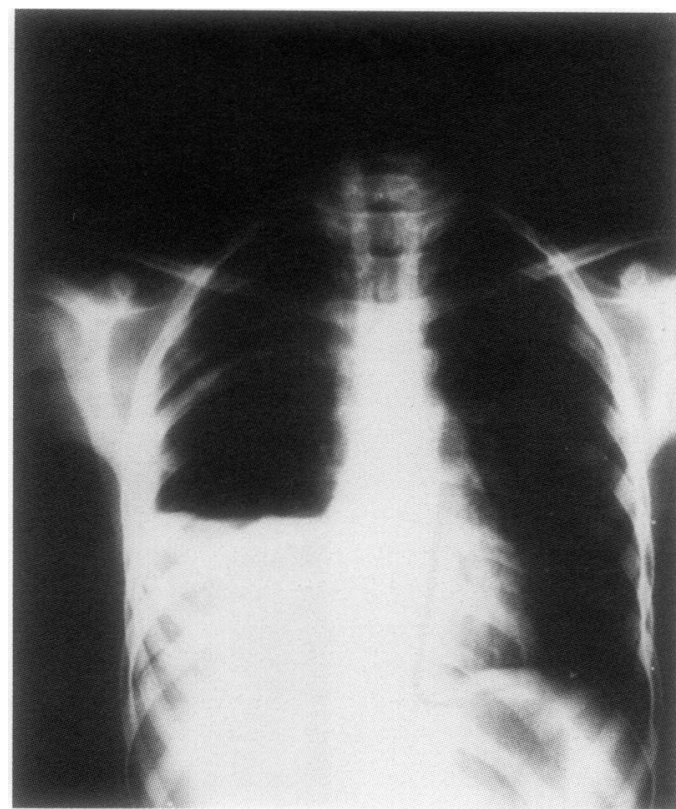

Figure 4 Chest radiograph showing a fluid and air-filled pulmonary cavity due to ruptured cyst in the right lung.

the bronchial fistulae and excising the redundant pericyst layer. Two patients with small cysts suffered persistent dry cough which, with occasional haemoptysis in one, persisted for six months in both patients although they eventually recovered. Plain chest radiographs were normal and, although bronchoscopic examination showed no evidence of bronchiectasis, crowding of the bronchial tree was seen which supports the view that this can be a problem with the use of purse string sutures. There was no evidence of wound infection in any patient. During three years of follow up only one patient had a recurrent hydatid cyst at the site of a previous one.

\section{Discussion}

The clinical features and distribution of the pulmonary hydatid cysts in our patients are similar to others. ${ }^{5-9}$ In the surgical management of hydatid cysts removal of intact cysts is essential. It is advantageous to remove the cyst intact without injecting it with scolicidal agents because the fluid in the cyst is under tension ${ }^{6-12}$ and spillage may follow injection. After removal of the intact cyst, or its remnants, the pericyst cavity remains with its bronchial openings. These bronchial fistulae are best sutured with non-absorbable material. ${ }^{101314}$ The management of these cavities has been considered by many. ${ }^{9-13}$ Although resection of the affected lobe allows removal of intact cysts, avoids sec- ondary hydatidosis from spillage, and solves the problem of the residual cavity, it is a radical method. ${ }^{59111215}$ Like others, therefore, we believe that resection should be avoided whenever possible in children, particularly in endemic areas. ${ }^{581114}$ After removal of the endocyst and excision of the redundant pericyst some authors keep the residual cavity open (without obliteration) to the adjacent pleural cavity as it $\overrightarrow{\bar{F}}$ will be repleuralised later. ${ }^{61011}$ In early reports Barret and Thomas ${ }^{1314}$ described the closure of small pericyst cavities with purse string sutures. This procedure was later named endoplication and capitonage. ${ }^{7912}$ To our knowledge there $\frac{2}{0}$ has been no mention in the literature of a technique for eradicating large cavities situated $\overrightarrow{0}$ deep in the parenchyma by any method other $\overrightarrow{\vec{H}}$ than purse string sutures. In these cavities we $\stackrel{\omega}{\omega}$ used the long axis method in nine patients and have subsequently done this in adults as well.

In conclusion, we recommend that resection of hydatid cysts should be avoided. Small cystic cavities can be left open or obliterated by purse $\mathscr{Q}$ string sutures after closure of the bronchial 은 openings. For larger cavities long axis obliteration with interrupted sutures is re- $\frac{D}{0}$ commended. These methods can be applied in adults as well as children.

We acknowledge $\mathrm{Mr}$ Rajab Alsheltami who prepared the photographs and slides for this paper. Our thanks go also to Ms Vivian B Florido and Mr Edgar D Sicat for typing the manuScript.

1 Shambesh MK, Macpherson CNL, Beastly WM, Gusbi A, Elisions T. Prevalence of human hydatid disease in North Western Libya: a cross-sectional ultrasound study. Ann Trop Med Parasitol 1992;86:381-6.

2 Dar FK, Taguri S. Epidemiology and epizootiology of hydatidosis in the Libyan Jamahiriya, and recommendations for a program of surveillance and control of the disease. Garyounis Med f 1979;24:11-5.

3 Morris DL, Gould SG. Serum and cyst concentrations of mebendazole and flubendazole in hydatid disease. $B M \mathcal{F}$ 1982;285:176.

4 Aggarwal P, Wali JP. Albendazole in the treatment of pulmonary echinococcosis. Thorax 1991;46:599-600.

5 Xanthakis D, Ethimiadis M, Papadakis G, Primikrios N, O Chassapakais G, Roussaki A, et al. Diseases of the chest (report of 91 patients surgically treated). Thorax 1972;27: (report of 91 patients surgically treated). Thorax 1972;27:

6 El Hasani NB. Pulmonary hydatid disease in childhood. $f\}$ $R$ Coll Surg Edinb 1983;28:112-5.

7 Solak H, Ozgan G, Yuksek T, Eren H, Sdak N, Hirca NK, 윽 et al. Surgery in hydatid cyst of the lung. Scand $\mathcal{f}$ Thorac Cardiovasc Surg 1988;22:101-4.

8 Slim MS, Akel SR. Hydatidosis in childhood. Prog Pediatr

9 Durg 1982;15:119-29. et al. Surgical treatment of hydatid cyst on the lung - N et al. Surgical treatment of hydatid cyst on the lung - O

10 Saidi F. Surgery of hydatid disease. London, New York: WB Saunders, 1976

11 Tsakayiannis E, Pappis C, Mouseates G. Late results of conservative surgical procedures in hydatid disease of the lung in children. Pediatr Surg 1970;68:379-83.

12 Sarsam A. Surgery of pulmonary hydatid cyst. Review of $\mathbb{S}$ 115 cases. $\mathcal{F}$ Thorac Cardiovasc Surg 1971;62:663-8.

13 Barret NR, Thomas D. Pulmonary hydatid disease. $B r f \mathfrak{T}$ Surg 1952;40:222-44.

14 Barret NR. The anatomy and pathology of multiple hydatid cysts in the thorax. Ann R Coll Surg Engl 1960;26:162-379.

15 Mothaghian N, Mahmoudi S, Vadz-Zadreh K. A ten year survey of hydatid disease (Echinococcus granulosus) in children. Prog Pediatr Surg 1982;16:95-112. 